Molecules 2005, 10, 492-507

molecules

ISSN 1420-3049

http://www.mdpi.org

\title{
Review
}

\section{Reaction of Nitrilimines and Nitrile Oxides with Hydrazines, Hydrazones and Oximes}

\author{
Abdel-Rahman S. Ferwanah ${ }^{1}$ and Adel M. Awadallah ${ }^{2, *}$ \\ ${ }^{1}$ Chemistry Department, Faculty of Science, Al-Azhar University of Gaza, P.O. Box-1277, Gaza, \\ Palestine. Fax: (+970) 8-2823180, E-mail: ferwanah@hotmail.com \\ ${ }^{2}$ Chemistry Department, Faculty of Science, Islamic University of Gaza, P.O. Box-108, Gaza, \\ Palestine. Fax: (+970) 8-2823310 \\ * Author to whom correspondence should be addressed; e-mail: awada@mail.iugaza.edu
}

Received: 18 May 2004; in revised form: 28 December 2004 / Accepted: 29 December 2004 / Published: 28 February 2005

\begin{abstract}
This review article discusses the reaction of nitrilimines and nitrile oxides with hydrazines, hydrazones, and oximes. Three reaction modes were observed. The article mainly covers our work published over the last fifteen years, in which interesting heterocyles such as oxadiazoles, triazoles, and tetrazines were synthesized and fully characterized.
\end{abstract}

Keywords: Nitrilimines, nitrile Oxides, hydrazines, hydrazones, oximes.

\section{Introduction}

The concept of 1,3-dipoles was first introduced by Huisgen in 1963 [1]. Since that time, a lot of work has been done on their reactions and the mechanism of 1,3-dipolar cycloaddition. A comprehensive review discussing the chemistry of 1,3-dipoles appeared in 1984 [2]. Numerous significant papers have been published over the last two decades on the reaction of nitrilimines and nitrile oxides with substituted hydrazines, hydrazones and oximes. Different aspects of these reactions will be outlined in this short review. 


\section{Nitrilimines and nitrile oxides}

Nitrilimines 2, also called nitrile imides, are transient intermediates in solution. The most common method for their generation is dehydrohalogenation of hydrazonoyl halides $\mathbf{1}$ in the presence of triethylamine $[2,3]$.

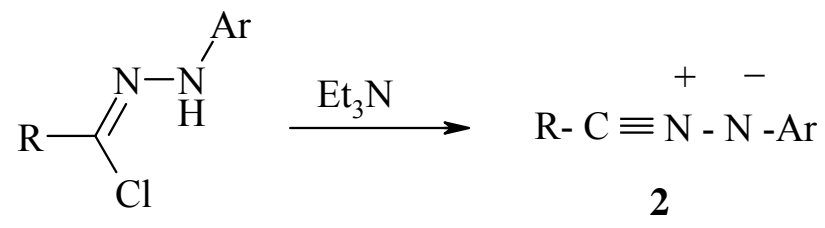

1

Likewise, nitrile oxides $\mathbf{4}$ are usually generated and trapped in situ; the most common method for their generation is dehydrohalogenation of $\alpha$-chloro-oximes 3 upon reaction with a base (usually triethylamine). Nitrile oxides dimerize easily and it is usually beneficial to generate them slowly at low temperature, in presence of the trapping agent, so their concentration remains low [2].

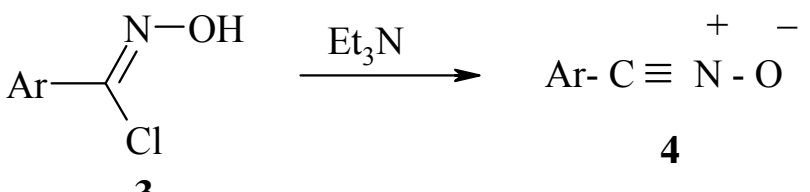

Both nitrilimines $\mathbf{2}$ and nitrile oxides $\mathbf{4}$ are widely used in the synthesis of different heterocycles. Three modes of reaction were observed for their reaction with different dipolarophiles [3]; namely:

i) Replacement reactions with nucleophiles $(\mathrm{Nu})$ leading to acyclic adducts:<smiles>[R]C(Cl)=NN[Al]</smiles>

ii) Cycloaddition reactions with multiple bonds leading to five-membered heterocycles. The reactions proceed with almost complete stereochemical control and a remarkable regiochemical control in many cases.<smiles>[Y][Y][Te]C(C)N</smiles>

iii) Cyclocondensation reactions with nucleophiles incorporating suitably located electrophilic centers leading to five- or six-membered heterocyclic rings. An example is the reaction of 
nitrilimines generated in situ from the respective hydrazonoyl halides $\mathbf{1}$ with $\alpha$-amino acid esters 5 leading to 4,5-dihydro-1,2,4-triazin-6-ones 6 [4].

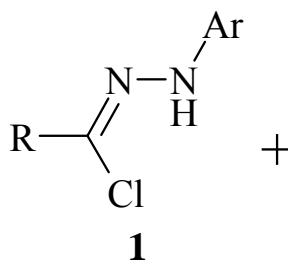

1<smiles>CCOC(=O)C(C)(C)N</smiles>

5

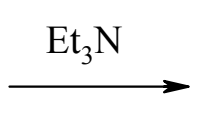

All the above modes of reaction were observed for the reaction of nitrilimines $\mathbf{2}$ and nitrile oxides 4 with differently substituted hydrazines, hydrazones and oximes.

\section{Reactions of Nitrilimines and Nitrile Oxides with Hydrazines}

Reaction with phenyl-, acetyl- and benzoylhydrazines

Nitrilimines undergo 1,3-additions with phenyl-, acetyl- and benzoylhydrazines 7 leading to the acyclic adducts $\mathbf{8 a}$ or $\mathbf{8 b}$ [5].

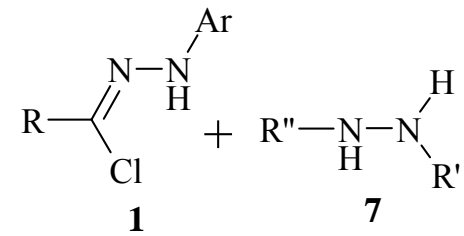

8a: $\mathrm{R}^{\prime}=\mathrm{H}, \mathrm{Ph}, \mathrm{C}(\mathrm{O}) \mathrm{CH}_{3}, \mathrm{C}(\mathrm{O}) \mathrm{Ph}$

$\mathrm{R}^{\prime \prime}=\mathrm{H}$

8b: $R^{\prime}=H$

$\mathrm{R}^{\prime \prime}=$ alkyl

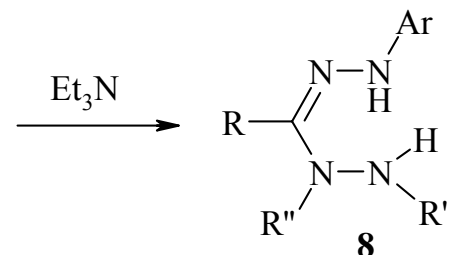

8

The reaction of nitrile oxides with hydrazine hydrate was similarly reported to give hydrazidoximes [6].

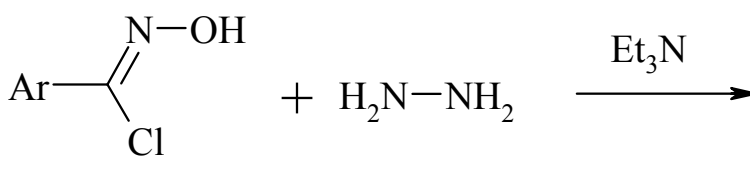

3<smiles>[R]C(=NO)NN</smiles>

9

Reaction with methylhydrazine

The reaction with methylhydrazine occurs at the $\mathrm{N}-\mathrm{Me}$ group, rather than the $\mathrm{NH}_{2}$ group, leading to the acyclic adducts $\mathbf{1 0}$ [7]. 
<smiles>[R]/C(Cl)=N/N[Al]</smiles><smiles>[R]/C(=N/N[Al])N(C)N</smiles>

A similar reaction was reported for the reaction of nitrile oxides with methylhydrazine to yield $\mathbf{1 1}$ $[6,8]$.<smiles>CNN</smiles>

3<smiles>CCN(C)[Al]C(=NO)N(C)N</smiles>

11

\section{Reaction with methoxycarbonylhydrazine}

The reaction of C-acetyl-N-aryl nitrilimines with methoxycarbonylhydrazine (12) afforded the acyclic adduct 1-methoxycarbonyl-2-[1-arylhydrazono-propane-2-one]hydrazine (13). Refluxing compound 13 with charcoal in toluene for six hours gave the oxidized product 3-acetyl-1-methoxycarbonyl-5-arylformazan (14) in high yield. No other cyclic products were observed [9].

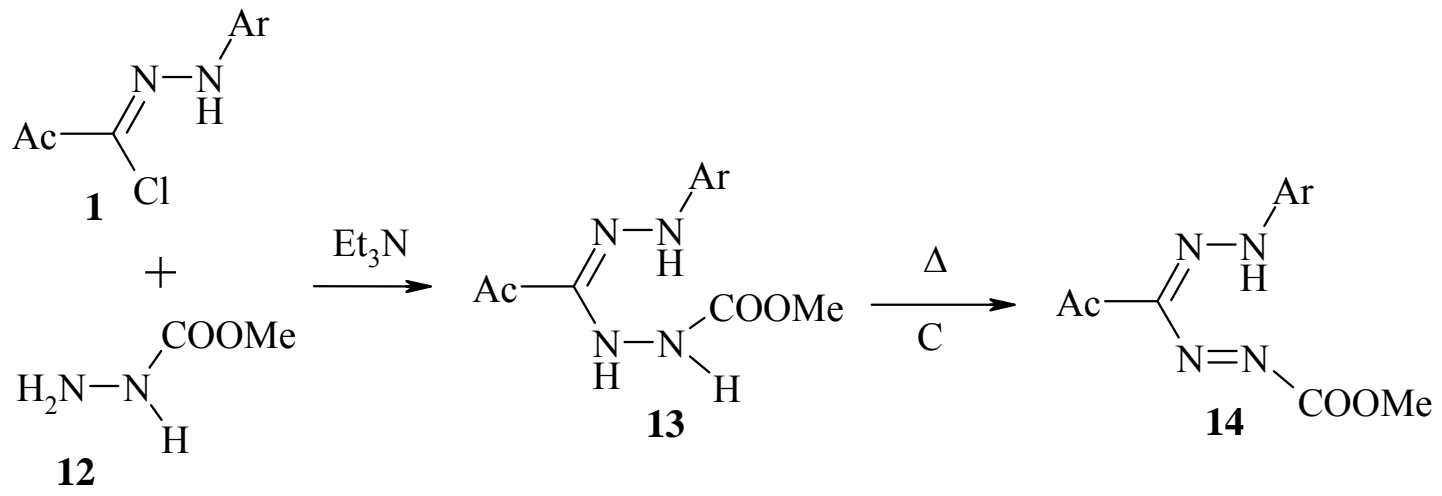

Similarly, nitrile oxides react with methoxycarbonylhydrazine (12) to give the acyclic adducts $\mathbf{1 5}$, albeit in poor yield (about 20\%).<smiles>O=[N+]([O-])c1ccc(/C(Cl)=N/O)cc1</smiles><smiles>CCN(C)CC</smiles><smiles>COC(=O)NN/C(=N\O)c1ccc([N+](=O)[O-])cc1</smiles>

15 
Reaction with 1-ethoxycarbonyl-1-methylhydrazine

This reaction gave the acyclic product 1-ethoxycarbonyl-1-methyl-2(1-arylhydrazonopropane-2one)hydrazine (17). Thermal oxidative cyclization of compound 17 gave unexpected products, as these were found to be the s-tetrazines $\mathbf{1 8}$ rather than the expected tetrazinones 19. Structural assignment of compounds 16 was based on elemental analysis, mass spectra, ${ }^{1} \mathrm{H}-{ }^{13} \mathrm{C}$ - and $2 \mathrm{D}-\mathrm{NMR}$ spectral data, including HMQC and HMBC experiments. These compounds exist as a pair of tautomers in solution. This reaction was carried out with C-acetyl [9], C-benzoyl- and C-2-naphthoyl nitrilimines [11].

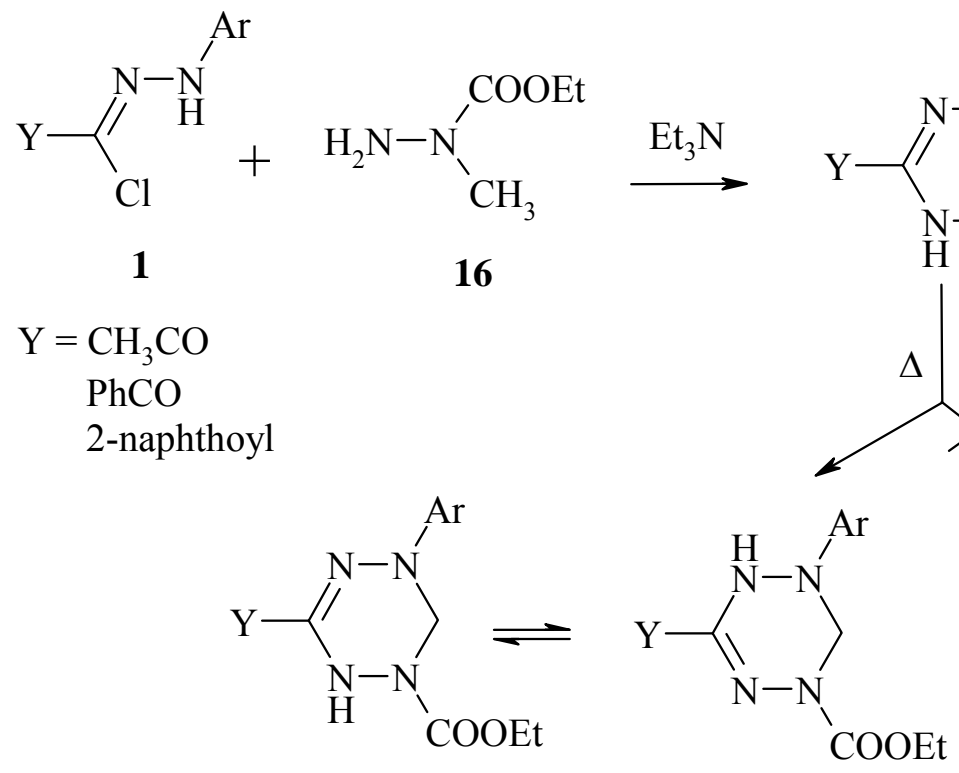

18<smiles>[Y]C1=NN([Al])C(=O)N(C)N1</smiles>

19

On the other hand, 1-ethoxycarbonyl-1-methylhydrazine (16) readily reacts with the nitrile oxide generated by the action of triethylamine on benzohydroxamoyl chloride, yielding the acyclic adduct 2-benzohydroxamoyl-1-ethoxycarbonyl-1-methylhydrazine (20) in moderate yield. The latter cyclizes almost quantitatively to the corresponding novel 4,5-dihydro-,1,2,4,5-oxatriazin-6-one (21) upon stirring with excess sodium hydride in dry tetrahydrofuran for $30 \mathrm{~min}$. at room temperature [11].

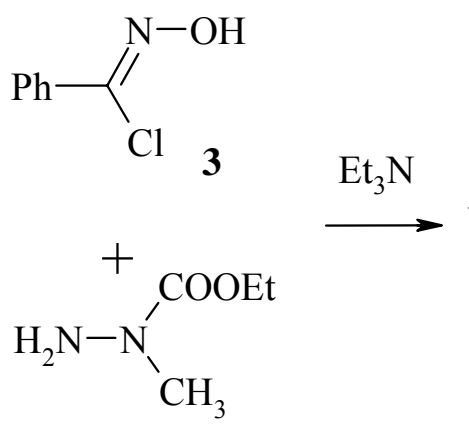<smiles>[Y]/C(=N/O)NN(C)C(=O)OCC</smiles>

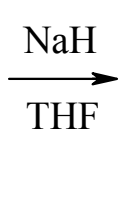

16 
Reaction with 1-acetyl- and 1-formyl-1-methylhydrazine

C-acetyl-, C-benzoyl- and C-(2-naphthoyl)nitrilimines react also with 1-acetyl- and 1-formyl-1methylhydrazines 22 to give the acyclic adducts 23. Thermal cyclization of the latter adducts gave tetrahydro-1,2,4,5-tetrazines 24. Dihydro-1,2,4,5-tetrazines 25 were also obtained upon elimination of formaldehyde from compounds 24 [12].

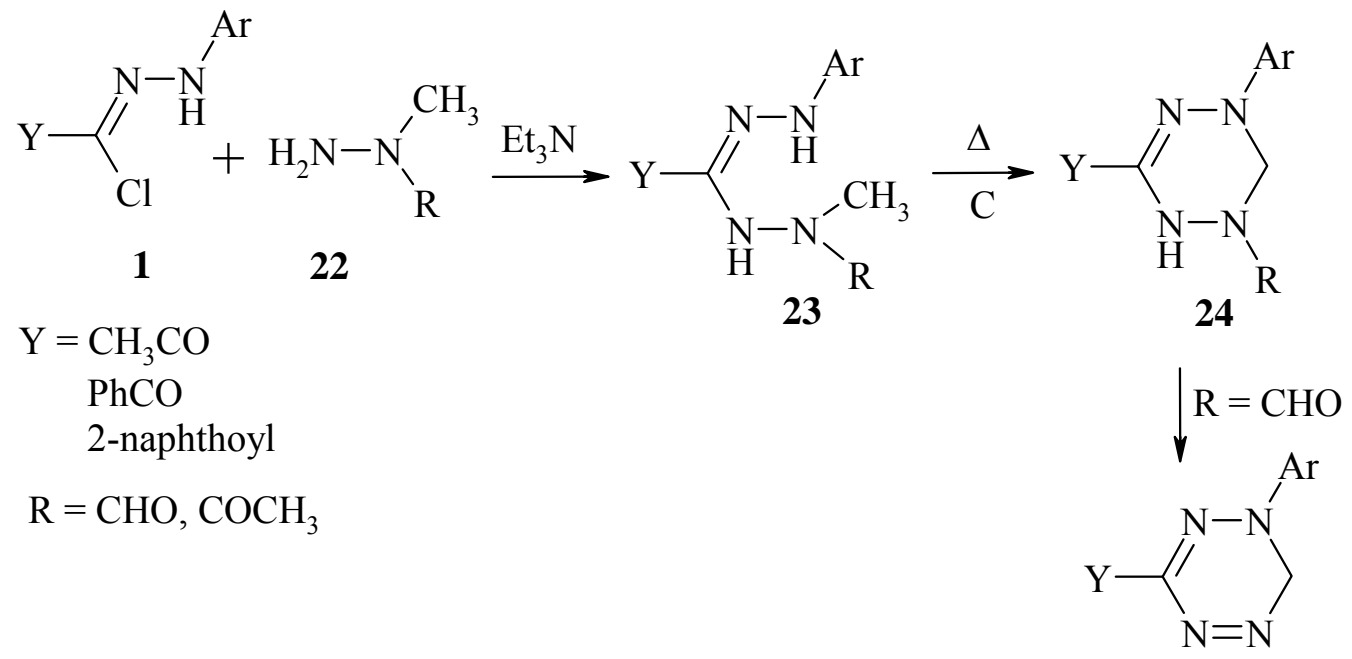

25

Reaction of nitrilimines with 1,1-dimethylhydrazine and 1-methyl-1-phenylhydrazine

C-acetyl-, C-benzoyl- and C-(2-naphthoyl)-nitrilimines react with 1,1-dimethylhydrazine and 1methyl-1-phenylhydrazine 26 giving the amidrazones 27 [12].

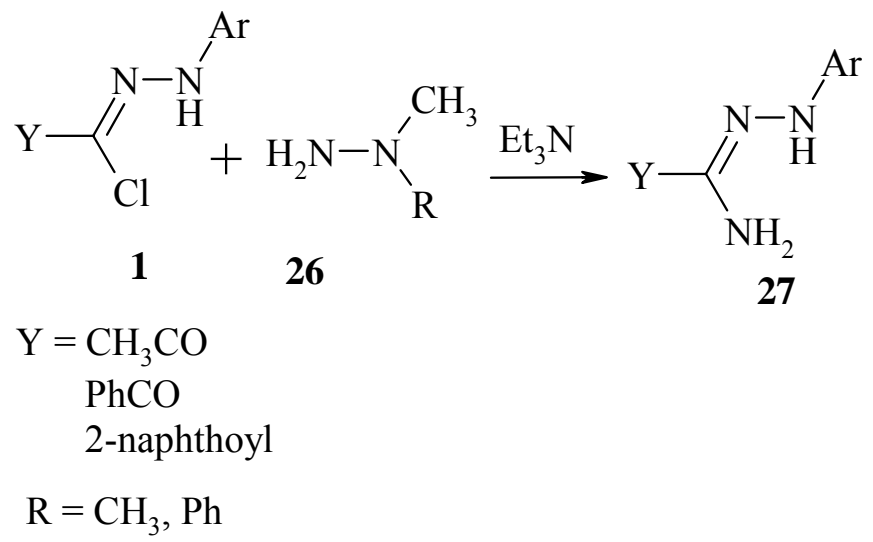

Reaction of nitrilimines with 1-ethoxycarbonyl-2-phenylhydrazine

This reaction gave the acyclic adducts 28. Refluxing $\mathbf{2 8}$ with charcoal in either toluene or xylene for several hours gave no reaction and the starting material was recovered unchanged [9]. 


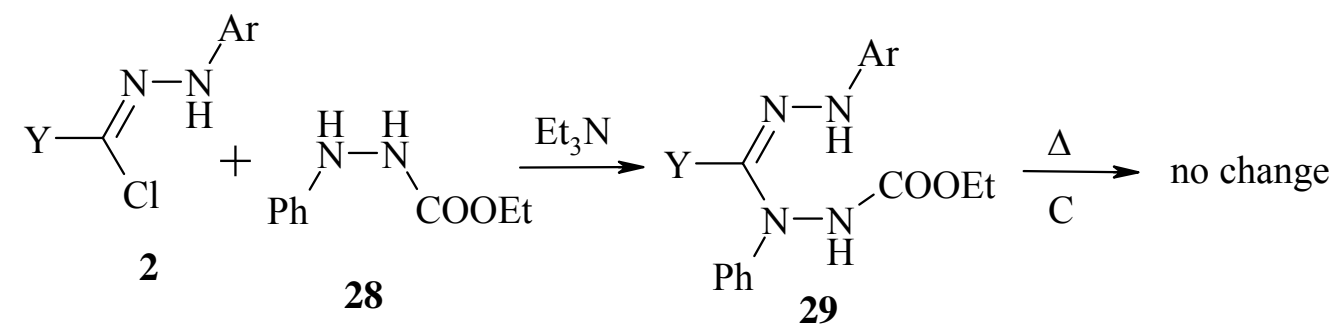

Reaction with ethyl hydrazinoacetate

Reaction of C-methoxycarbonyl nitrilimines with ethylhydrazino acetate (30) under mild conditions gave 4-amino-1-aryl-3-methoxycarbonyl-6-oxo-1,4,5,6-tetrahydro-1,2,4-triazines 31 [13].<smiles>CCN(C)CC(=O)OCCNNN</smiles>

On the other hand, the reaction of nitrile oxides with ethyl hydrazine acetate gave the acyclic adducts 32, which resulted from nucleophilic addition through the terminal $\mathrm{NH}_{2}$ followed by oxidation [14].
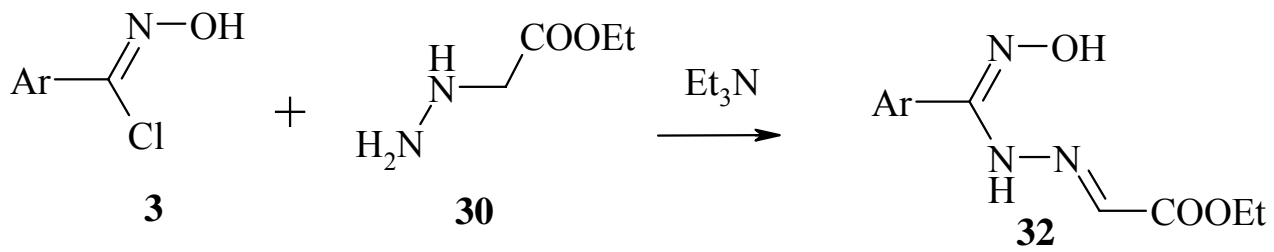

Reaction with hydrazones

Reaction with substituted simple hydrazones

Simple hydrazones derived from aliphatic aldehydes and ketones 33 reacted with C-acetyl- and Cmethoxycarbonyl nitrilimines at ambient temperature to furnish the acyclic products 34 . Attempts to cyclize the latter by heating in tetrahydrofuran or ethanol were unsuccessful. However, treatment of solutions of these acyclic adducts with $\mathrm{Pd}-\mathrm{C}$ at room temperature brought about oxidative cyclization to the orange-red coloured 1,6-dihydro-s-tetrazines 36 [15]. 


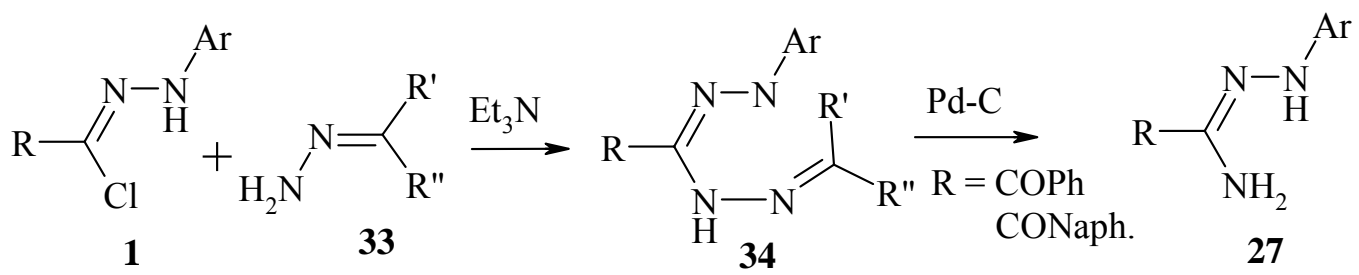

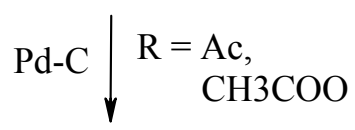<smiles>[R]C1=NN([Al])N([R])C([R7])([R])N=N1</smiles><smiles>[R]C1=NN([Al])C(CC)CC1</smiles>

36

Attempts to isolate the tetrahydrotetrazine intermediate 35 were generally unsuccessful. C-benzoyl and C-2-naphthoyl nitrilimines were also found to give acyclic adducts 34. However, these adducts gave a mixture of complicated products upon heating with $\mathrm{Pd}-\mathrm{C}$ from which amidrazones 27 were separated as the major products.

On the other hand, aryl nitrile oxides undergo 1,3-dipolar cycloaddition with alkanone hydrazones 33 to give the cycloaddition product 4-amino-3-aryl-5,5-dialkyl-4,5-dihydro-1,2,4-oxadiazole (37). The reaction with alkanal hydrazones gave, however, a complex mixture of intractable products, from which the oxadiazole 38 was the major product [17].

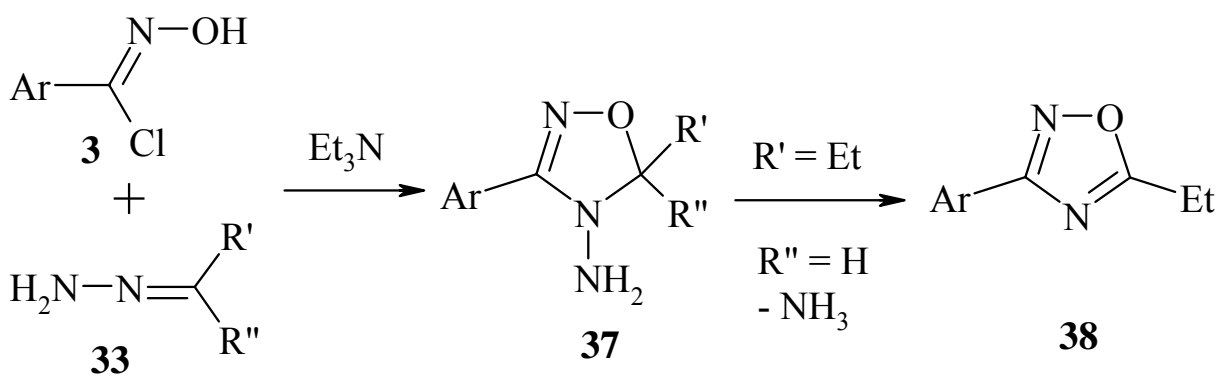

Reaction of hydrazones of aryl aldehydes and ketones 39 with nitrile oxides gave, however, the corresponding acyclic adducts $\mathbf{4 0}$, formed through nucleophilic addition of the hydrazones to nitrile oxides. 1,3-Dipolar cycloaddition across azomethine л-bond of the hydrazones was not observed here [18].

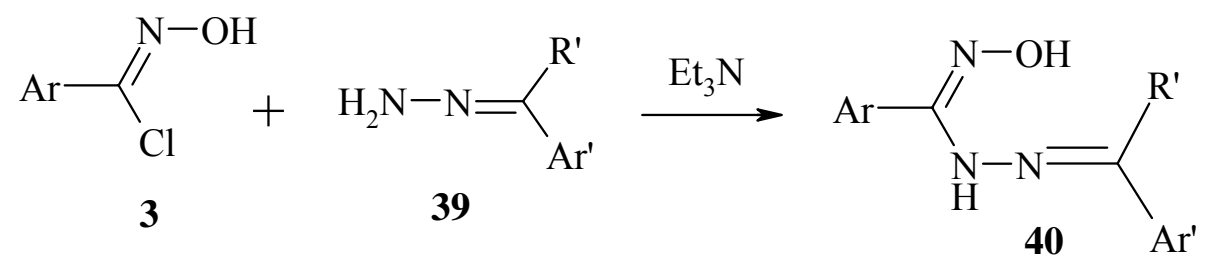


It is worth mentioning that acylation of the 4-amino-4,5-oxadiazoles 37 in refluxing toluene or treatment of the acyl derivatives of these compounds $\mathbf{4 1}$ with trifluoroacetic anhydride brings up ring transformation to the aromatic 1,3,4-oxadiazoles 42 [18].

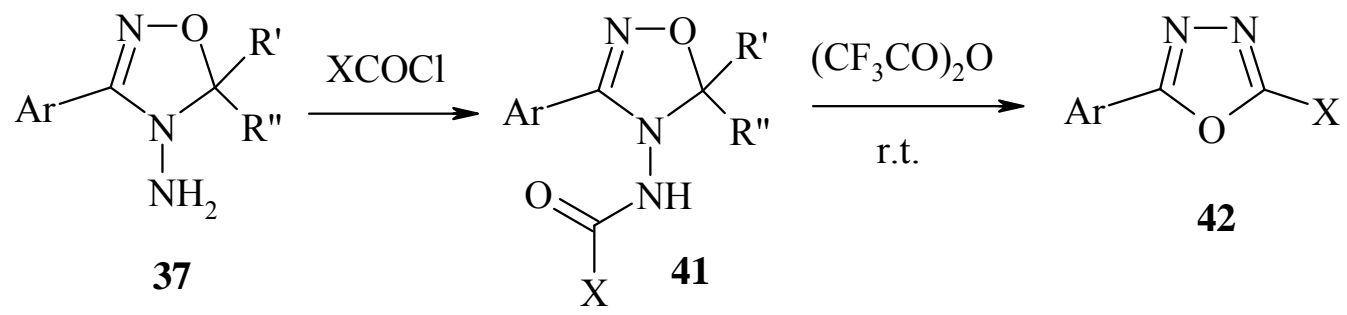

$$
\mathrm{X}=\mathrm{H}, \mathrm{CH}_{3}, \mathrm{Ph}, \mathrm{CH}_{2} \mathrm{Cl} \text {, }
$$

Similarly, 4-amino-4,5-dihydro-1,2,4-oxadiazole 37 are transformed into the corresponding 2arylamino-1,3,4-oxadiazoles $(\mathbf{4 4}, \mathrm{X}=\mathrm{O})$ or thiadiazoles $(\mathbf{4 4}, \mathrm{X}=\mathrm{S})$ via reaction with phenylisocyanate or phenylisothiocyanate, followed by brief treatment of the resulting adducts 43 with trifluoroacetic anhydride at ambient temperature [19].

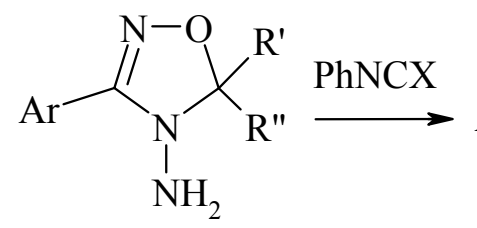

37<smiles>[X]C(Nc1ccccc1)NN1C([3H])=NOC1([R])[R]</smiles>

43<smiles>[X]C1=NN=C(Nc2ccccc2)[Al]1</smiles>

44

$\mathrm{X}=\mathrm{O}, \mathrm{S}$

Reaction of nitrilimines and nitrile oxides with substituted methylhydrazones

The interaction between methylhydrazones of aliphatic alkanones and alkanals $\mathbf{4 5}$ provided a direct synthetic route to 1,2,3,4-tetrahydro-1,2,4,5-tetrazines 46 [20].<smiles>[R]C(Cl)=NN[Al]</smiles>

The reaction with methylhydrazones of aromatic aldehydes and ketones $\mathbf{4 7}$ gave "ring-chain" tautomerism, where the tautomeric ratio was found to be dependent on the steric and electronic effects of the substituent at C-3, C-6 and N-4 [21]. 
<smiles>[R]C(Cl)=NN[Al]NC([R])=NN(C)C([R])=NN(C)C([Al])=NCC</smiles>

The reaction of nitrile oxides with methylhydrazones $\mathbf{4 5}$ in chloroform was found to constitute a convenient synthetic route to the novel 4,5-dihydro-6H-1,2,4,5-oxatriazines 49 [6].<smiles>[R]C(Cl)=NO</smiles>

Risitano and coworkers obtained the triazoles directly from the appropriate monomethylhydrazones of aryl aldehydes in refluxing ether for 2 hours [22].<smiles>[R]/C=N\NC</smiles><smiles>[R]C(=NO)N(C)/N=C(/[R])NCC</smiles>

1,2,3,4-tetrahydro-1,2,4,5-tetrazines 49, derived from methylhydrazones of aryl aldehydes, underwent ring contaction, via elimination of $\mathrm{H}_{2} \mathrm{O}$, to yield the respective $1 \mathrm{H}-1,2,4$-triazoles 51 . This transformation was envisaged to proceed via the ring-opened $(E)$-hydrazonoximes which then suffered dehydrative cyclization. The process is acid-catalyzed and was thermally induced. Apparently, the driving force for this transformation is linked to the aromaticity of the triazole product [8].<smiles>[R]C1=NOC([R])NN1C</smiles>

The reaction of nitrile oxides with 1,1-dimethylhydrazones 52 yields the cycloaddition products, the N,N-dimethylamino-oxadiazolines 53. 

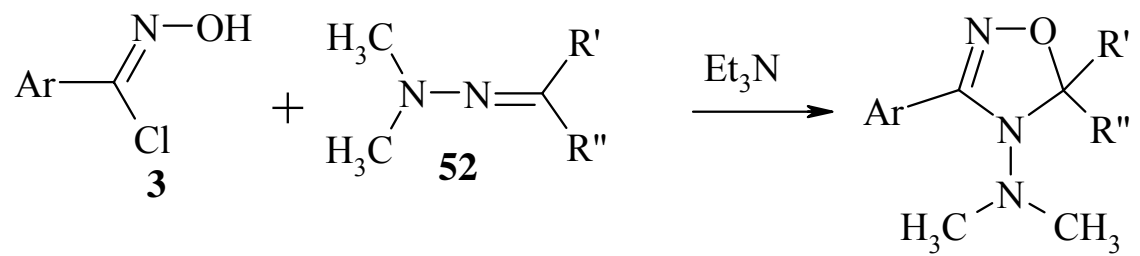

53

Reaction of nitrilimines with hydrazones carrying electron withdrawing groups

Hydrazonoyl halides reacted with alkanone and cycloalkanone alkoxycarbonylhydrazones $\mathbf{5 4}$ to give the cycloaddition products 4,5-dihydro-1,2,4-triazoles 55, rather than the tetrazine cyclocondensation products 56 [23].

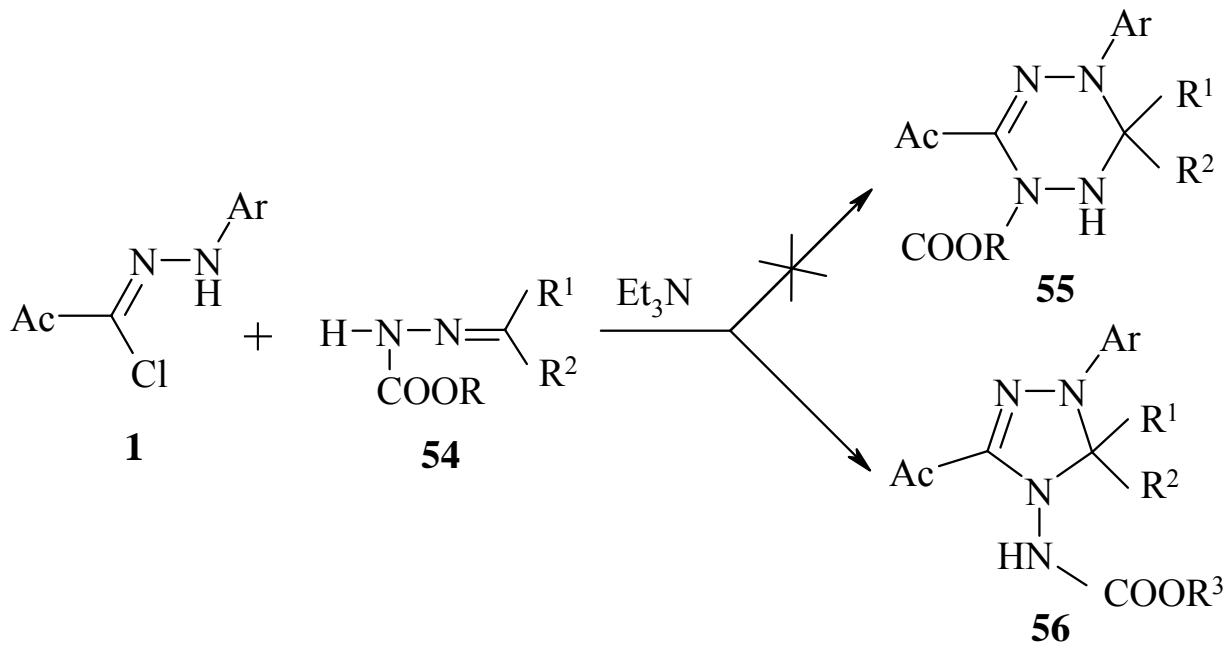

\begin{tabular}{|c|c|c|c|c|c|c|c|c|}
\hline & $\mathbf{a}$ & b & c & d & e & f & g & $\mathbf{h}$ \\
\hline $\mathrm{R}^{1}, \mathrm{R}^{2}$ & $\mathrm{Me}, \mathrm{Me}$ & $\mathrm{Et}, \mathrm{Et}$ & & & & & & \\
\hline $\mathrm{R}^{3}$ & $\mathrm{Me}$ & $\mathrm{Me}$ & $\mathrm{Et}$ & Et & Et & $\mathrm{Et}$ & Et & Et \\
\hline$X$ & $\mathrm{Cl}$ & $\mathrm{Cl}$ & $\mathrm{Cl}$ & $\mathrm{Br}$ & $\mathrm{Cl}$ & $\mathrm{Cl}$ & $\mathrm{Cl}$ & $\mathrm{Cl}$ \\
\hline
\end{tabular}

The ${ }^{1} \mathrm{H}-\mathrm{NMR}$ spectra showed a signal at $6.5-7.0 \mathrm{ppm}$ characteristic for the $\mathrm{N}-\mathrm{H}$ of the five membered ring compounds 55. The N-H of the six membered ring structure 56 is expected to appear at 4-5 ppm [1]. Signal doubling is observed both in the ${ }^{1} \mathrm{H}$ - and ${ }^{13} \mathrm{C}-\mathrm{NMR}$ spectra of compound $\mathbf{5 5 f}$ containing the 4-methylcyclohexane moiety due to tautomeric isomerism. The ${ }^{13} \mathrm{C}-\mathrm{NMR}$ spectra display the characteristic signals of the suggested structures. The signal for C5 (quaternary or spiro carbon) appears in the range of $80-90 \mathrm{ppm}$. This was similar to reported values of quaternary and spiro carbons flanked by two nitrogens in five-membered heterocycles. This provided strong evidence in support of structures 55, rather than the six-membered heterocyclic structure 56, which was expected to have a C6 signal at about $70 \mathrm{ppm}$. 
<smiles>[17N]NN=C([AlH2])Cl</smiles>

1<smiles>CC(=O)NN=C(C)C</smiles>

57

$\mathrm{Ar}^{\prime}=4-\mathrm{Cl}-\mathrm{C}_{6} \mathrm{H}_{4}$ $\mathrm{Ar}=\mathrm{COPh}, 2$-naphthoyl

\begin{tabular}{c|cccc}
\hline & $\mathbf{a}$ & $\mathbf{b}$ & $\mathbf{c}$ & $\mathbf{d}$ \\
\hline $\mathrm{R}, \mathrm{R}$ & $\mathrm{Me}, \mathrm{Me}$ & $\searrow$ & $\searrow \square$ & e \\
\hline
\end{tabular}<smiles>[X]C(=O)NN1C(C([Y17])=O)=NN([AlH2])C1([R])[R]</smiles>

Similarly, alkanone and cycloalkanone hydrazones 57 carrying electron withdrawing groups $\left(\mathrm{OCOCH}_{3}, \mathrm{COCH}_{3}, \mathrm{COPh}\right)$ react with $\mathrm{C}$-benzoyl- and $\mathrm{C}$-2-naphthoyl nitrilimines to give the cycloaddition triazole products 58. IR, ${ }^{1} \mathrm{H}-\mathrm{NMR},{ }^{13} \mathrm{C}-\mathrm{NMR}$ and mass spectral data are consistent with the assigned triazole ring system. Compounds 58 having an acetyl group, showed signal doubling in their ${ }^{13} \mathrm{C}$-NMR spectra, apparently, owing to their presence as two different mesomeric structures [24]. Ferwanah et al. also reported the synthesis of another series of these triazoles $\mathbf{6 0}$ from the reaction Cacetyl-N-arylnitrilimines (2) with acetaldehyde, alkanone and cycloalkanone benzoylhydrazones 59. Intersting spiro compounds containing heteroatoms were prepared from this reaction [25].<smiles>[Mg]C(Cl)=NN[Al+2]</smiles>

1<smiles>[R]C([R])=NNC(=O)O</smiles>

59

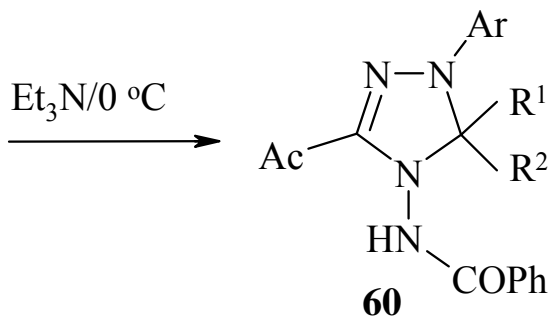

60

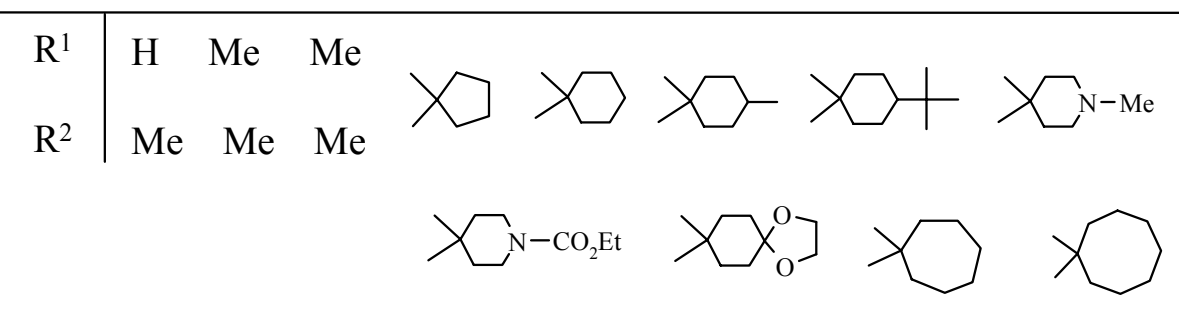

C-methoxycarbonyl hydrazonoyl halides 2 were also found to react with substituted hydrazones of alkanone, cycloalkanone and heterocyclic ketones 57 to give the cycloaddition products 3methoxycarbonyl-4,5-dihydro-1,2,4-triazoles 61 [26]. 


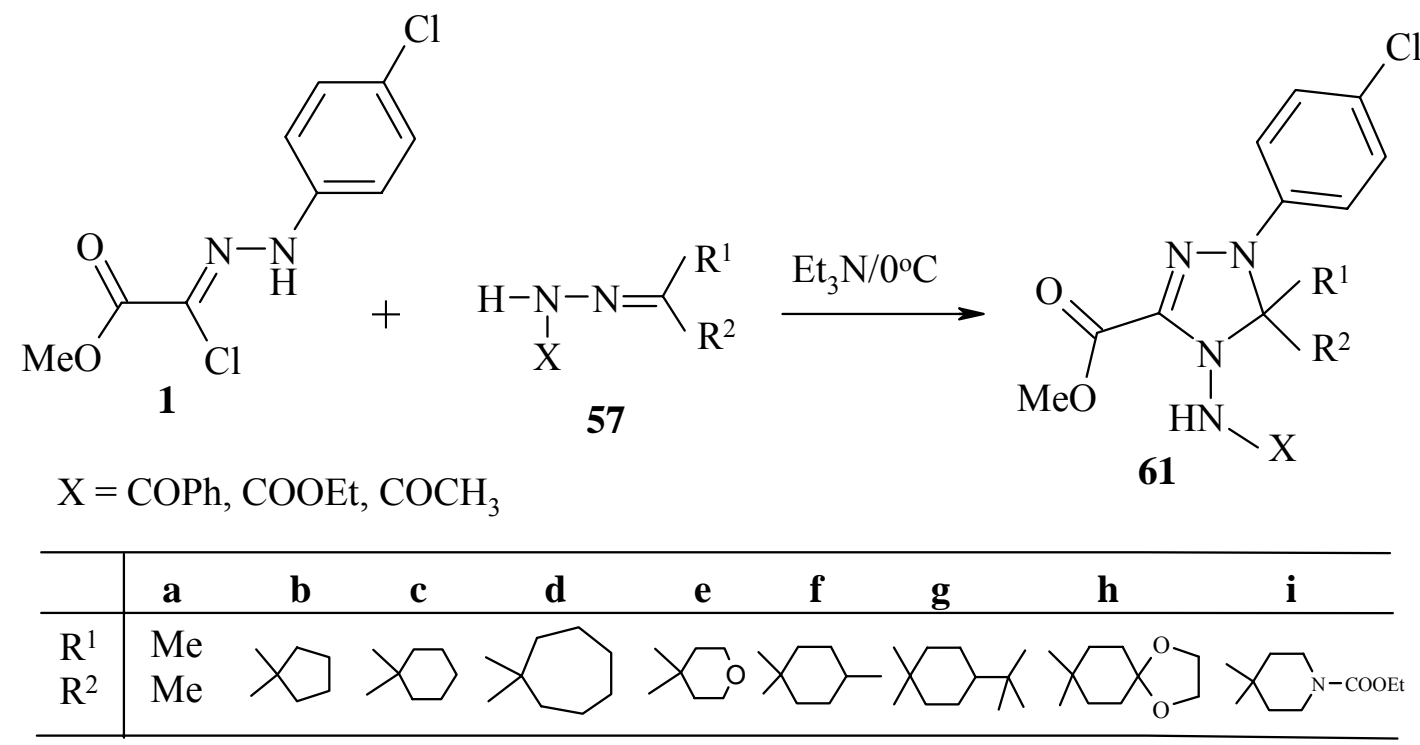

\section{Reaction with Oximes}

Acetone oxime 62 readily reacted with nitrilimines yielding the unexpected 3-acetyl-4,5-dihydro5,5-dimethyl-1H-triazoles 63 in moderate yields. The 4-hydroxytriazoles 64 were not observed. Structural assignment of the resulting triazoles was based on elemental analysis, and spectral data including MS, IR, ${ }^{1} \mathrm{H}$ - and ${ }^{13} \mathrm{C}-\mathrm{NMR}$ spectal data. Further evidence was obtained from ${ }^{15} \mathrm{~N}-\mathrm{NMR}$ spectra, which displays a doublet for the $\mathrm{NH}$ at $284.26 \mathrm{ppm}$ relative to nitromethane $\left({ }^{1} \mathrm{~J}_{\mathrm{N}-\mathrm{H}}=85 \mathrm{~Hz} ;{ }^{3} \mathrm{~J}_{\mathrm{N}}\right.$ $\left.\mathrm{CH}_{3}=2.5 \mathrm{~Hz}\right)[27]$.

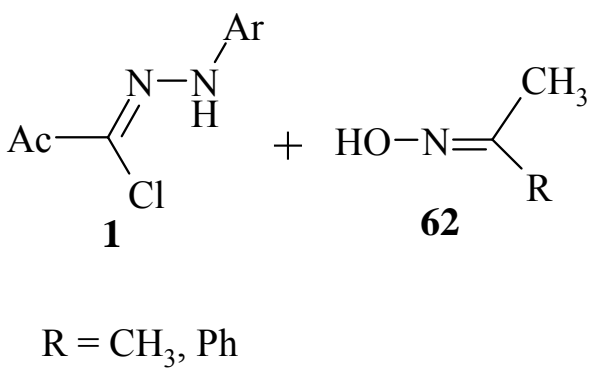

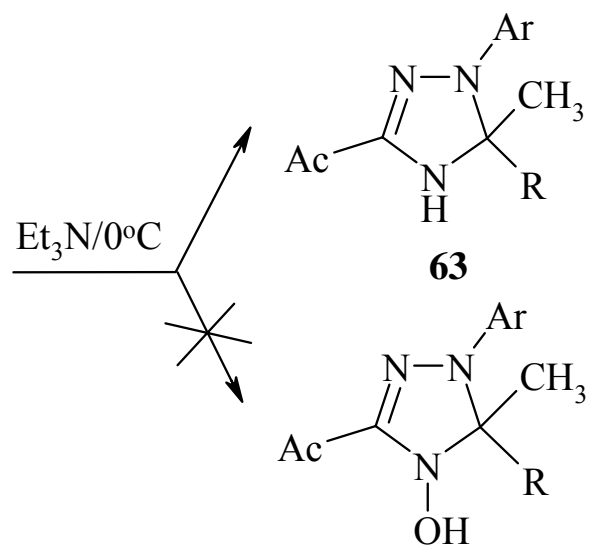

64

Nitrilimines reacted similarly with acetophenone oxime to afford the corresponding triazaoles 63. Similarly, the reaction with 1-methyl-4-piperidone oxime 65 yields the respective spiro triazoles 66 [28]. 
<smiles>CCN(CC)C(C)(C)C1=NN([Al])C2(CCN(C)CC2)N1</smiles>

The reaction with cycloalkanone oximes 67 gave the heterocyclic spiro triazoles 68 in moderate yields [29].<smiles>[R]CCCC[R]</smiles>

$\mathrm{Y}=$ Ac, 2-naphthoyl<smiles>[R]CC1([R])NC([Y]2CCCCC2)=NN1[Al]</smiles>

68

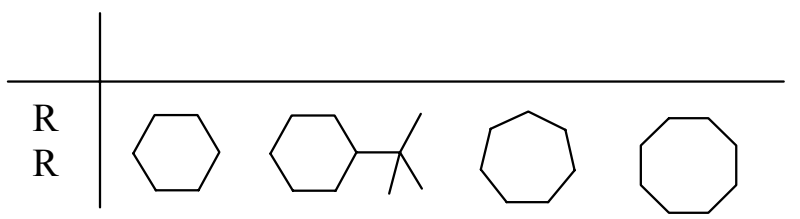

Reaction of triazoles $\mathbf{6 1}$ with acetyl chloride or acetic anhydride gave the ring transformation product 1-Aryl-3-acetyl-5-methyl-1H-1,2,4-triazole 70 instead of the expected N-acetyl derivative 69. This ring transformation was believed to start with $\mathrm{N}$-acylation of the dihydrotriazole to form the corresponding $\mathrm{N}$-acetyl derivative, which extruded the acetone via a four-membered ring intermediate and recyclizes to the aromatic triazole suggesting the conversion sequence $(\mathbf{6 1}) \rightarrow(\mathbf{6 9}) \rightarrow(\mathbf{7 0})$ [29].

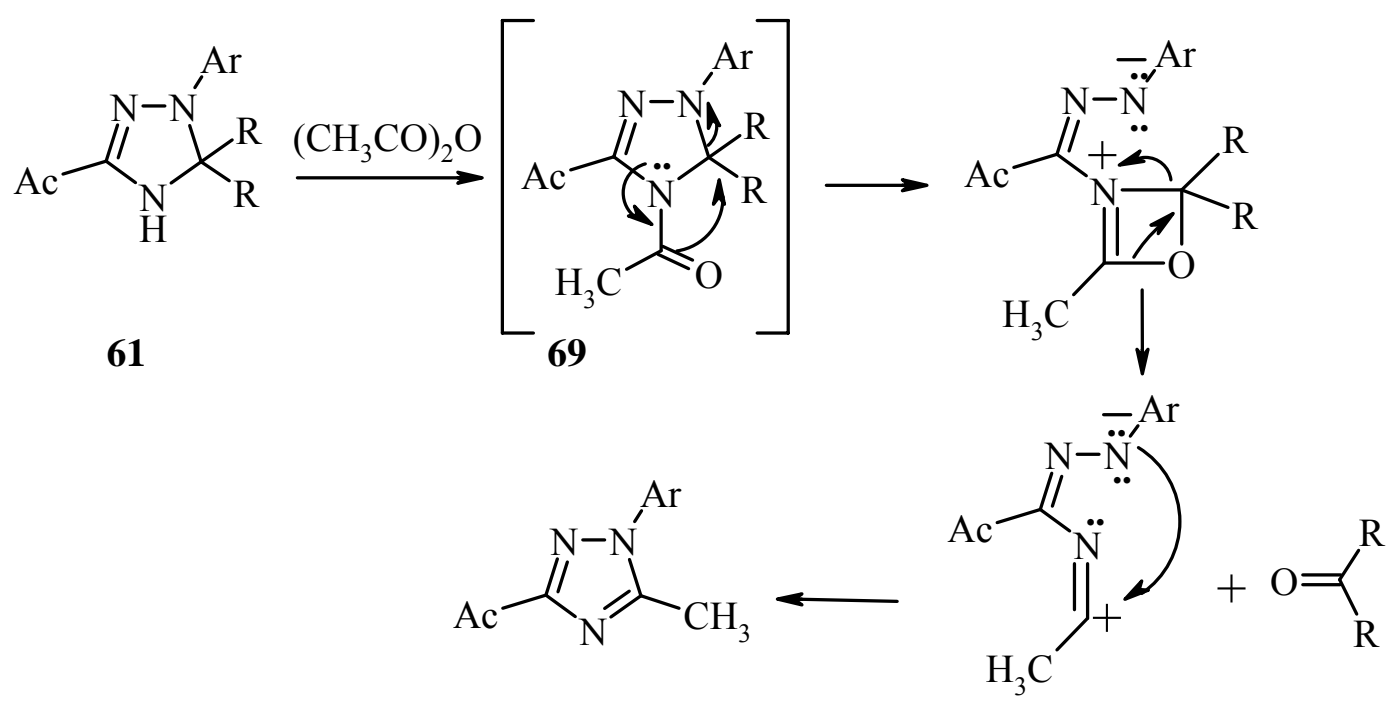

70

On the other hand, the reaction of nitrile oxides with oximes 62 was reported to give the 4-hydoxy4,5-dihydro-1,2,4-oxadiazolines 71 [30]. 

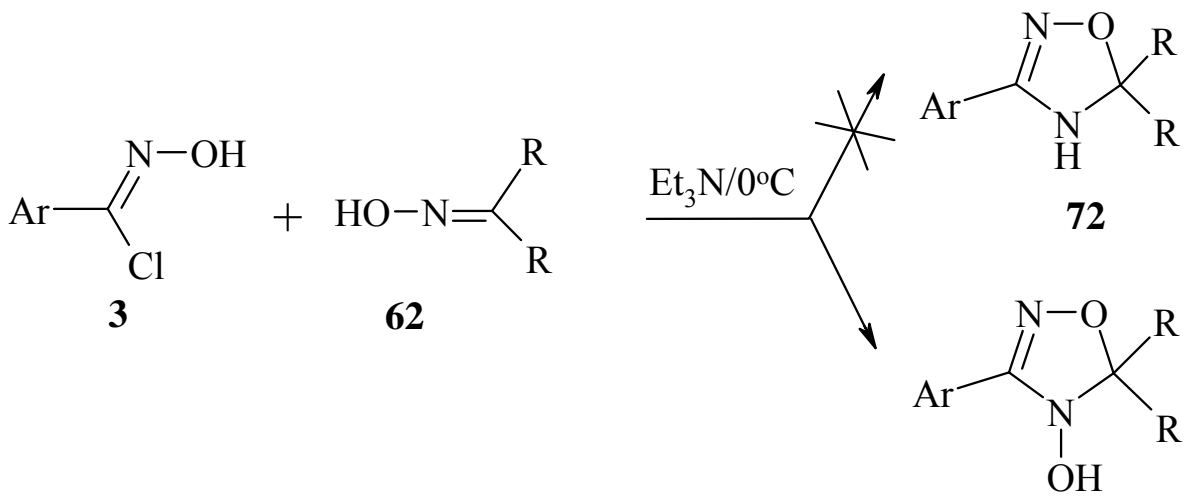

71

\section{Conclusions}

Nitrilimines and nitrile oxides react with hydrazines giving acyclic adducts. The acyclic adducts resulting from the reaction of 1-substituted-1-methylhydrazines with nitrilimines cyclize to give s-tetrazines, and those resulting from the reaction of nitrile oxides with 1-ethoxycarbonyl-1methylhydrazine cyclize to oxatriazinones upon stirring with sodium hydride. The reaction of nitrilimines with hydrazones give the acyclic adducts which also cyclize to s-tetrazines. The reaction with nitrile oxides gives, however, the 1,3-dipolar cycloaddition oxadiazole derivatives. s-Tetrazines and oxatriazines were obtained from the reaction of methylhydrazones with nitrilimines and nitrile oxides, respectively. Hydrazones carrying electron withdrawing groups react with nitrilimunes affording the respective cycloaddition triazole products. Ketooximes react with nitrilimines yielding the respective triazoles.

\section{References}

1. Huisgen, R. Angew. Chem. Intern. Ed. Engl. 1963, 2, 256

2. 1,3-Dipolar Cycloaddition; Padwa, A. ed.; Wiley-Interscience: New York, 1984.

3. (a) Shawali, A. S. Heterocycles 1983, 20, 2239; (b) Shawali, A. S. Chem Rev. 1993, 93, 2731.

4. El-Abadelah, M. M.; Saleh, S. A.; Awadallah, A. M. Asian J. Chem. 1997, 9, 474.

5. Hegarty, A. F., Aylwand, J. B.; Scott, F. L. J. Chem. Soc. (C) 1967, 2587.

6. Hussein, A. Q.; El_Abadelah, M.M.; Hodali, H. H.; Kamal, M. R., Aouf, M.M. Heterocycles 1987, 26, 2199.

7. Hassaneen, H. M.; Mousa, H. A.; Nosrat, K. M. Heterocycles 1988, 27, 695.

8. El-Abadelah, M.M.; Hussein, A. Q.; Nazer, M. Z.; Musa, O. M.; Rademacher, P.; Bandmann, H. Heterocycles 1993, 36, 455.

9. El-Haddad, M.; Ferwanah, A. R. S.; Awadallah, A. M. J. Prakt. Chem. 1998, 340, 623.

10. Awadallah, A. M.; Ferwanah, A. R. S.; El-Sawi, E. A.; Dalloul, H. M. Heterocyclic Commun. 2002, 8, 369.

11. Ferwanah, A. R. S.; Awadallah, A. M. Asian J. Chem. 1998, 10, 180.

12. Ferwanah, A. R. S.; Awadallah, A. M.; El-Sawi, E. A.; Dalloul, H. M. Synth. Commun. 2003, 33, 1245.

13. El-Abadelah, M. M.; Nazer, M.; El-Abadlah, N. S.; Meier, H. J. Prakt. Chem. 1997, 339, 90. 
14. Awadallah, A. M.; unpublished data.

15. Hussein, A. J. Chem. Res (S), 1996, 174; J. Chem. Res (M), 1996, 949.

16. El-Sawi, E. A.; Awadallah, A. M.; Ferwanah, A. R. S.; Dalloul, H. M. Asian J. Chem. 2002, 14, 1225.

17. El-Abadelah, M. M.; Hussein, A. Q.; Awadallah, A. M. Heterocycles 1989, 29, 1957.

18. El-Abadelah, M. M., Nazer, M. Z.; Hussein, A. Q.; Awadallah, A. M.; Rademacher, P.; Woydt; M. J. Heterocycl. Chem. 1991, 28, 1229.

19. Hussein, A. Q.; El-Abadelah, M. M.; Nazer, M. Z.; Awadallah, A. M.; Rademacher, P.; Bandman, H. Heterocycles 1994, 38, 981.

20. El-Abadelah, M. M.; Hussein, A. Q.; Kamal, M. R.; Al-Adhami, K. H. Heterocycles 1988, 27, 917.

21. (a) Hussein, A. Q.; El-Abadelah, M. M.; Al-Adhami, K.; Abushamla, A. S. Heterocycles 1988, 29, 1136; (b) El-Abadelah, M. M.; Hussein, A. Q.; Abushamla, A. S. J. Prakt. Chem. 1991, 333, 61; (c) El-Abadelah, M. M.; Hussein, A. Q.; Saadeh, H. A. Heterocycles 1991, 32, 1063; (d) Boese, R.; El-Abadelah, M. M.; Hussein, A. Q.; Abushamleh, A. S. J. Heterocyclic Chem. 1994, $31,505$.

22. Risitano, F.; Grassi, G.; Fote, F. J. Chem Res. (S), 1981, 65; J. Chem.. Res. (M), 1981, 831.

23. Awad, B. M.; Ferwanah, A. R. S.; Awadallah, A. M.; El-Halabi, N. M. Asian J. Chem. 2002, 14, 1235.

24. Awadallah, A. M.; El-Sawi, E. A.; Ferwanah, A. R. S.; Dalloul, H. M. Asian J. Chem. 2002, 14, 1230.

25. Ferwanah, A. R. S. Synth. Commun. 2003, 33, 243.

26. Awadallah, A. M.; Ferwanah, A. R. S.; El-Haddad, M. R.; Schrader, W. Asian J. Chem. 2004, 16, 1691

27. Ferwanah, A. R. S. Asian J. Chem. 1999, 11, 480.

28. Ferwanah, A. R. S.; Awadallah, A. M.; Khafaja, N. A. Asian J. Chem. 2001, 13, 1203.

29. Ferwanah, A. R. S.; Kandile, N. G.; Awadallah, A. M.; Miqdad, O. A. Synth. Commun. 2002, 32, 2017.

30. Morrocchi, S.; Ricca, A. Chim Ind. (Milan) 1967, 49, 629.

(C) 2005 by MDPI (http:www.mdpi.org). Reproduction is permitted for noncommercial purposes. 